



\section{Digitized by the Internet Archive in 2011 with funding from University of Toronto}



CONTRIBUTIONS OF THE ROYAL ONTARIO MUSEUM DIVISION OF ZOOLOGY AND PALAEONTOLOGY

No. 49

ROYAL ONTARIO MUSEUM LIBRARIES

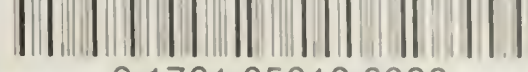

31761050136928

SCENT RECEPTORS IN LEPIDOPTERA

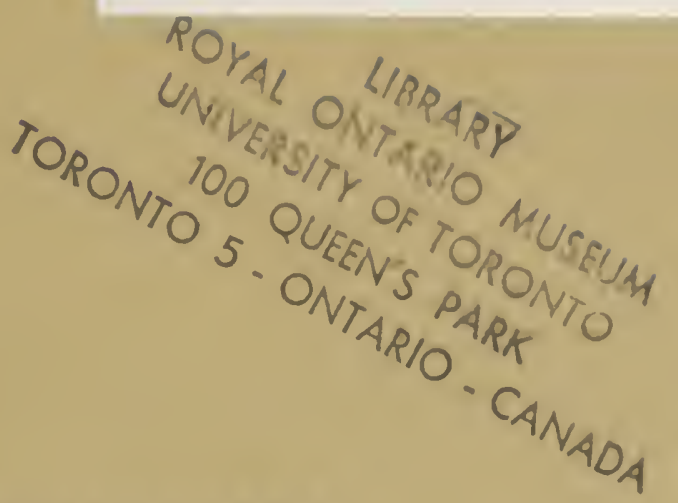

By

F. A. Urquhart

100 Queen's Park

TORONTO, CANADA

April 22, 1958 

CONTRIBUTIONS OF THE ROYAL ONTARIO MUSEUM DIVISION OF ZOOLOGY AND PALAEONTOLOGY

No. 49

\title{
SCENT RECEPTORS IN LEPIDOPTERA
}

\author{
By \\ F. A. Urquhart
}

100 Queen's Park

TORONTO, CANADA

April 22, 1958 



\title{
SCENT RECEPTORS IN LEPIDOPTERA
}

\author{
By F. A. URQuhakT
}

A consideration of the so-called "seent glands" that occur on the wings of some species of butterflies

Is the males of many species of Lepidoptera certain scales of the wings appear to be different in size and configuration from the majority of the scales. These have been termed androconia and are believed to be associated with scent glands. It is further believed that these "scent scales" produce some sort of aroma which "assists the male butterfly in locating a mate," presumably the female being attracted to the male.

Modified scales, or hairs, that are apparently associated with the production of scent have been described for the Ithomyidi, various genera of Nymphalinae, a genus of Morphinae, the Hesperidi, and many others. As far as I have been able to ascertain, no author has been able to associate such modified hairs or scales with a functional secretory gland or produce evidence for assuming the production of a fluid that might be responsible for the odour produced. Further, the odour produced by the butterfly, or butterflies, in question has been assumed to emanate from these modified hairs or scales with no evidence to indicate that such is the exact origin of the scent. It would be most difficult indeed for man's poorly developed olfactory organs to locate the pin-point origin of an odour associated with a small patch of scales or hairs, and even if observations would seem to point to such an origin, it has never been adequately demonstrated that the scent arises directly from the scales or hairs rather than being transported to such areas from some other part of the body. Scudder was aware of the weakness in assuming that such scales are responsible for the production of the scent when he wrote in his book, The Butterflies of the Eastern United States and Canada, ". . . there are not a few instances known in which the statement regarding the source of the odor is somewhat vague, a gland being referred to when the specification of such an organ is a collection of scales of peculiar character."

With respect to the odour emitted, most authors agree that it is a sweet-smelling scent resembling that given off by various species of flowers, as for example, lilac, violet, syringa, thyme, verbena, orange, and so on. Müller refers to it in one species as a "very delicious perfume." Of those who have referred to the odour as "disagreeable" it is more than likely that the scent was not produced by the male during sexual excitement. That most authors have compared the 
scent to that produced by flowers is most significant, as we shall see later in the present discussion.

Concerning the structure and function of the "scent glands" on the hind wings of the Monarch butterfly, a paper written by S. A. Housman dealing with this subject was published in The American Naturalist. The following information was supplied by the author and the following conclusions rendered:

1. The scent organ of the Monarch butterfly is a slightly elevated black pouch about three millimetres in length and one and one half millimetres in width.

2. The darkly coloured scales which cover it are similar to those found in the dark areas of the wings.

3. The cavity of the sac is lined with tiny, black, overlapping scales which are much smaller and more delicate than the surface scales and more heavily pigmented. These are the "scent scales" or "androconia."

4. The inner wall of the sac itself is thin, yellowish, and with regularly arranged circular areas, so-called "scent cups."

5. Each scent cup is covered with a thin cuticle bearing a minute central pore from which extends an extremely narrow, hair-like scale, similar to a seta.

6. Fitted into such pores are the scale stalks or pedicels in contact with the unicellular gland cells of the epidermis.

7. In areas between the cups are pits in which are located the pedicels of wide scales.

8. These two types of scales give off characteristic odours and would account for the term "scent scales" and for reference to the sac as a "scent gland" or an area of "sensory scales."

9. Secretion from specialized gland cells escapes in the regions of the pedicels to coat the surfaces of the scales, and thus these modified insect hairs serve as outlets for cell secretions.

10. The secreting substance has a faint, fragrant odour likened to the sweet milkweed blossoms.

11. It may serve, in function, as a sex stimulant in that it is attractive to the opposite sex.

As I shall point out later in the discussion, there is no evidence for the conclusion that the two types of scales give off characteristic odours and hence there is no reason for terming these scales "scent scales." There is no evidence for stating that there are specialized gland cells and that secretions coat the scales. The flower-like perfume may not originate from the specialized scales. 
Longstaff in his excellent book Butterfly Hunting in Many Lands records translations of Fritz Müller's papers dealing with hair tufts, felted patches, and similar structures on the wings of male Lepidoptera. The following statement concerning Danaus gilippus and D. crippus is significant in the present discussion: "It is not possible to detect any odour arising from the wings of the males of either of the two species found in the Province of S. Catharina.... If one strongly compresses the abdomen, there is everted on each side of the last segment a finger-shaped membranous tube with closed apex, which is covered with dark hairs, erected as the tube passes out of the abdomen, and exhaling at the same time a somewhat strong odour in D. gilippus, and one less strong though still perfectly distinct in D. erippus." The author further points out that it "appears extremely unlikely that such a function (namely the production of scent) would be exercised by a cavity communicating with the air only by a narrow slit, and, in addition, having apparently no mechanism on the wing by means of which it could be opened." It has been suggested that these sexual spots may be rudimentary in function resulting from the development of the abdominal scent glands. Doubleday et al. pointed out that in some males of D. erippus a small portion of the wing, close to the orifice of the sexual cavity, is denuded of scales as if they had been repeatedly rubbed away by introducing something into the slit. This I have also observed and would add that not only are the scales absent at the entrance to the sexual cavities but this particular area is slightly concave, forming a cup-like depression, the presence of which lends further support to the conclusions set forth in the discussions that follow. Muiller suggests that the substance produced by the sexual spots is transferred to the tip of the male abdomen.

In many species of Lepidoptera there are no sexual pouches, similar to those found in the danaids, but there are patches of modified scales or hairs on various parts of the wings or, in some cases, on the thorax. Epicalias acontius possesses a felt-like patch of scales on the lower surface of the front wings which, when at rest, lies over a similar patch on the upper surface of the hind wings. Myscelia orsis males possess a similar felt-like patch on the upper surface of the hind wings. In the Ithomyidi a tuft of long hairs is located near the front margin of the hind wings of the males which apparently emits a vanilla-like odour. In Prepona, one of the Nymphalinae, there is a similar tuft of black hairs on the hind wings of the males. The males of Thaumantis, a genus of Morphinae, have hair tufts of a similar nature on the upper surface of the hind wings near the base. In species of Antirrhea, one of the Satyrinae, the males are said to produce a strong odour from a patch of scales located on the hind wings at the anterior base of the upper surface, which is covered by 
the fore wings and protected by a covering mane of pale buff hairs. Stichophthalma (Morphinae) has a patch of modified scales and an erectile wisp of hairs on the hind wings of the male. A species of Ageronia (Nymphalinae) possesses two large, brown spots situated between the wings, where they oppose each other, which appear to be associated with emitting a scent. In Leptalis (Pierinae) there is a patch of scales associated with production of scent on the portions of the front and hind wings which conceal each other. In the case of Melete the odour is most pronounced when the wings are openedthe odour being retained when the wings are closed. It is interesting to note that, according to Scudder, Aurivillius "looks askant at the so-called scent scales described by Fritz Müller because he could detect no odour from Mancipium brassicae even though large androconia were present." This is a very interesting observation and one which will be readily answered in the discussion that follows.

In summary we may conclude that: (1) there are modified hairs and/or scales on the wings or thorax of male butterflies which are associated with the emission of a flower-like scent; (2) in most cases these modified scales are located on the hind wings of the male; (3) in some instances no detectable odour is associated with such modified scale areas; (4) abdominal glands producing a flower-like odour are present in the males of most species which possess modified scale patches; (5) the degree of modification of scales varies from a simple, almost unchanged, patch of scales, through those in which the scales are highly modified and densely clustered, and culminates in the advanced development of a partly closed pocket as found on the hind wings of the males of the Monarch butterfly. It should also be emphasized that many observations indicate that these specialized patches are often covered by similar patches on the underside of the front wings, or by a mantle of hair.

Before presenting what I believe to be the true function of the so-called "scent glands" on the hind wings of the male Monarch butterfly, I present the following data.

\section{Field Observations}

During the past twenty-two years, while engaged in a study of the migratory habits of the Monarch butterfly, I have made numerous observations on the mating habits of this particular species. To summarize these observations and to present more clearly an explanation for the function of the modified scale patches which I would term the scent receptors of the male, a single case involving one set of observations is here described dealing with a particular pasture field during the months of July and August in 1956. This particular field supported a very rich growth of milkweed (A. syriaca) 
as well as other flowering plants on one half of it, and a short grass area supporting small milkweed shoots and seedlings on the other half. The reason for this difference was that part of the field had been cut in order to obtain sod for the banks of an adjacent highway and the other part was left uncut because a small creek meandering through this particular area made cutting impossible. We had collected and tagged many Monarch butterflies in this field between 1952 and 1956 and, from our recorded data, there was a marked difference in sex ratio, $92 \%$ being males and $5 \%$ females. Although we were well aware of this peculiar sex ratio we were at the time only interested in tagging and hence did not study the situation. It was not until the summer of 19.56 that this sex ratio became an important factor in our studies of the migration, because eggs were required for rearing purposes. Many hours were spent searching for eggs on the leaves of the tall plants and only a few were found and these were located on the small, slender leaves associated with the flower clusters. Males were observed resting upon the broad leaves of the bush-like hawthorn trees, and the occasional female was seen flying from flower to flower-usually during the late afternoon. On July 26 it was noticed that a number of Monarch butterflies were flying close to the ground in the cut-over area, and on further investigation it was found that all of them were females and that they were depositing their eggs upon the leaves of small milkweed seedlings. While awaiting the approach of a female, the male could be seen resting upon the leaf of the hawthorn tree, his wings at times out-stretched and at other times partly closed. The apical half of the abdomen was raised and, when the wings were partly folded, the abdomen could be seen moving in a somewhat jerky fashion from side to side. From time to time, the male would leave its chosen resting place to survey the neighbouring field or to feed upon the nectar of the flowers, returning again to the hawthorn tree. By waiting beside the tree it was possible to capture the returning male and examine it. The abdominal scent glands could be extruded by gently pressing the tip of the abdomen and in so doing a flower-like perfume could be immediately detected. The odour was remarkably similar to that produced by species of flowers belonging to the genus Spiraca. When a female, having left the part of the field where oviposition took place, entered that part where the flowering plants were located, she was immediately pursued by the waiting male. It is interesting to note that the female was not attracted to the bush where the male lay in hiding, but, on the contrary, the male pursued the female, even from some considerable distance (up to 80 feet clistance) from his resting place. On many occasions the male would pursue a chipping sparrow, a song sparrow, a leaf or a piece of paper blown by the wind. If the female was overtaken by the male she might elude him by a rapid zig-zag flight or, with fluttering wings, fly vertically. In the latter case, 
the male would circle about the female, thus presenting a vertical spiral flight. Eventually, but not in every case, the male, now slightly in front of the female, would fly towards a nearby hawthorn bush pursued by the female. They would alight upon the leaf, the male often strutting beside or in front of the female, his wings slightly outstretched, the rear wings widely separated from the front wings. Then, while the female with wings folded or but slightly separated remained motionless, the male would curve his abdomen sideways so as to reach the tip of the abdomen of the female and thus grasp her firmly with his well developed jaw-like claspers. It is interesting to note that during this performance the proboscis of the female would be slightly or completely extended as if feeding upon some secretion on the surface of the leaf. I was unable, however, to locate such a fluid on the surface of the leaf. After resting in this position for a variable period of time, the male would eventually take to wing carrying the female suspended beneath him.

It should be noted that copulation took place regardless of the fact that the female had been ovipositing and hence had previously mated. From the examination of the bursa it was found that three matings were not unusual.

Occasionally one male would pursue another. A rapid vertical spiral flight would ensue, each male trying to get in front of the other. Such flights were much more rapid than when a male and female were involved, and eventually they would part, one returning to the nearby hawthorn bush and the other flying rapidly to a more distant location across the field.

\section{Examination of the Male During Mating and Non-Mating Periods}

During the height of the mating season, if a male is held in the hand a faint perfume may be detected. This odour cannot be detected out-of-doors, at least I have not been able to detect it under such conditions, but indoors, away from distracting odours, it is detectable. If the tip of the abdomen is pressed so as to cause the extrusion of the abdominal glands then a very decided odour can be detected even under out-of-doors conditions. It would appear that the odour emanating from the wings is very faint and that from the anal glands very strong, by contrast.

Before the mating season begins, as for instance during the overwintering period, no such perfume can be detected when the butterfly is held gently in the hand. If the abdomen is squeezed, and the glands are thus protruded, then the perfume can be detected although it is not as strong as during the mating season. This would seem to indicate that there is no perfume emanating from the wings during the nonmating periods, nor is the odour produced by the anal glands as strong. 
The accompanying drawings of the various scale configurations were made by using a microscope equipped with a camera lucida and hence represent fairly accurate outlines as well as being of the same magnification. The scales on the membrane of the wing are oval in shape and they may be smoothly rounded at the apex or with a slight serration or notch. The scales on the vein of the wing are elongate. The scales located on the top of the scent receptors are similar in shape to those found on the wing membrane. These scales are, however, much more numerous and form a dense mass. Approaching the slit-like entrance of the scent receptor the scales of the wing membrane become more elongated and those possessing serrated or notched apices become more numerous. Within the cavity of the scent receptor, the scales are much smaller, very black in colour and with slight or decidedly serrated apices. These scales have been referred to as "scent scales" or "androconia." In addition to these very numerous, closely packed scales there are a few hair-like scales.

\section{Examination of Scent Receptor}

By embedding the portion of the wing bearing the scent receptor taken from a freshly killed specimen (not one preserved in alcohol or the like) in paraffin, it is possible to make a transverse section through the receptor so as to view the parts in relation to each other. This is shown in the accompanying illustration taken from a camera lucida drawing. It is seen that the membrane of the wing, located next to the second cubitus vein ( 1 ) is folded in such a manner as to form a pocket with a narrow slit-like opening (2). There is a small opening (3) between the cavity of the second cubitus vein and the cavity which is enclosed by the upper and lower wing membranes (4) and now forming the roof of the receptor. The chitinous membrane (5) of the roof of the receptor is of the same thickness as that of the adjacent vein, and it remains thick until after it has curved into the cavity of the receptor, at which point (6) it becomes extremely thin-so thin, in fact, that it is difficult to detect in gross section. I refer to this flap-like portion of the receptor as a lip. This very thin membrane forms the wall (7) of the receptor cavity. It will be noted that it becomes thick again just prior to union with the wing membrane (8).

Attached to this thin membrane and with peg-like bases that penetrate into it, are numerous small black scales set into goblet-like structures, which structures I would term poscula (sing. posculum) from the latin meaning a goblet. There are also a few hair-like scales that are set into minute pores located in the centre of saucer-like structures, which structures I would term patellae (sing. patella) from 
the latin meaning a saucer. Many of these patellae do not posses scalelike hairs. The thin membrane lying between the poscula and patellae is thrown into shallow irregular folds.

A fluid, originating in the second cubitus vein, passes through the minute opening (3) and fills the cavity (4) where it becomes transformed into a white, spongy, wax-like substance. If the second cubitus vein, or the roof of the receptor, is punctured with a fine pin, the fluid will flow out and, on coming in contact with the air, will form a white, wax-like covering on the pin identical to that found on the floor of the receptor.

If the receptor taken from a live male is dissected under the microscope it is quite easy to remove the white, waxy substance from it. If this substance is placed in chloroform it immediately dissolves, exhibiting no cellular structure.

\section{Anal Scent Glands}

As I have pointed out above, if the apex of the abdomen of the male is squeezed a pair of finger-like, bright yellow glands will appear. These glands, which I have termed anal scent glands, are covered with very long, light brown hairs. When first extruded the hairs are clumped together forming a stiff, brush-like structure, but when fully extended the hairs stand out at almost right angles to the surface of the gland. Accompanying the extrusion of the glands there is a decided flower-like perfume produced. By squeezing the abdomen firmly, a portion of the rectal tissue is forced out which, like the anal glands, contains a yellow fluid and yellow tissue. The yellow fluid oozes through the thin membrane producing a large yellow drop. When this liquid is smeared on the fingers the flower-like odour is very strong.

\section{Position of Scent Repectors on the Wing in Relation to the Tip of the Male Abdomen}

There are many places on the hind wings, as well as on the front wings, where the so-called "scent glands" might be located. It is interesting to note, however, that they are located on the upper surface of the hind wings in a position such that they can be readily touched by the tip of the abdomen, as I have indicated in the accompanying illustration which was drawn to scale by tracing the outline of the wings and the abdomen. The fact that these structures are so located in relation to the tip of the abdomen may be readily demonstrated by bending the abdomen of the male slightly and moving it to the right or left.

The scent receptor is a pocket-like structure formed by a folding of the wing membrane, as outlined above. If the function of this structure 
was simply that of producing a secretion that attracted the female, then the opening could face in any direction. However, the slit-like opening faces the abdomen and is so located that the tip of the abdomen can be quite easily pressed against it.

\section{Experimentation}

A portion of the wing, bearing a seent receptor, was taken from a live male and placed under the microscope. The tip of the abdomen of the male was pressed so as to produce a drop of yellow liquid from the rectal tissue. Using a fine dissecting pin, the drop was taken from the tip of the abdomen and placed at the opening to the scent receptor. Within a few seconds the drop of liquid had been absorbed by the scent receptor. Dissection of the latter showed that not only were the seales within the receptor covered with the fluid but the underlying wax-like material had also absorbed it.

The experiment was repeated, using a drop of water. The drop remained in a spheroidal shape and was not absorbed.

\section{Summary}

From the above discussion the following may be deduced:

1. The female is not attracted to the male.

2. The male pursues the female in areas where flowering plants are present.

3. Following the nuptial flight the female follows the male.

4. The proboscis of the female is uncoiled as if attempting to feed.

5. A male awaiting a female may be seen to raise the abdomen so that the tip of it comes into contact with the scent receptors.

6. A fluid, produced by anal glands and the tissue (perhaps from rectal papillae?) of the rectum, bears a flower-like odour, which is most noticeable during the mating season.

7. A flower-like odour appears to be present on the wings during the mating season but is much fainter than that from the anal glands and rectal tissue.

8. A wax-like substance of a spongy nature, soluble in chloroform, is present in the scent receptor and is derived from a fluid originating in the second cubital vein. This fluid is believed to be derived from the thorax and conveyed to the receptor by the cubital vein.

9. The odoriferous fluid from the anal glands and rectal tissue is absorbed by the scent receptors. 


\section{Conclusion}

It is concluded that the so-called "scent glands" located on the hind wings of the male Monarch butterfly are actually "scent receptors" receiving the odoriferous fluid from the anal glands and rectal tissue and that the specialized scales become coated with the fluid and at the same time direct it to the poscula and patellae where it enters through minute pores in the thin chitin into the absorbent material beneath.

\section{Purpose of Scent Receptors and Function During Mating}

In most species of animals the male is attracted to and pursues the female. That this has an important function in maintaining a vigorous species has long been realized. The stronger male of those contending for a given female usually succeeds in final copulation. The female, in contrast, shows little or none of this aggressiveness and hence, we may assume, does not possess a positive urge towards copulation.

Confining our discussion to the Monarch butterfly: The male, being the aggressor, pursues the female. Since copulation cannot take place during flight, it is necessary for the male and female to come to rest together. The female, possessing no inclinations towards copulation, would continue in flight. In order to lure, as it were, the female to rest, the male produces, from anal glands, a substance that, in so far as the human olfactory organs are concerned, resembles the odour of flowers. The female, surrounded by this aroma produced during the mating flight is attracted to it and hence follows the male to the place of his choosing. Alighting upon the leaf of a plant, the female seeks the origin of the aroma, hence the reason for the uncoiling of the proboscis, and while she is so involved the male is able to seize the tip of the female's abdomen with his strong chitinous, jawlike claspers. Having thus secured the female, copulation can take place. It is obvious why the male does possess such powerful clasping organs, strong enough to bear the weight of the female while he is in flight.

The scent receptors perform a most interesting function in the mating role. While engaged in the nuptial flight the anal glands may be extruded, thus producing a heavy aroma of flowers. The anal glands may remain extruded while he fans his wings in front of the female when she is resting upon the surface of the leaf. Once the male attempts to secure the tip of the female's abdomen with his claspers, however, the anal glands must be retracted. When the anal glands are retracted the aroma of flowers would also dissipate. In order to continue to surround the female with the aroma, a small quantity of the fluid is introduced into the scent receptors and these 
then take over for the brief period when clasping, prior to copulation, is taking place. The fluid is introduced into the scent receptors most likely during the strutting and famning phase just prior to clasping, although, as pointed out above, it is not unusual to see the operation in progress while the male is awaiting the arrival of a female.

I have pointed out that in some species there is simply a cluster of scales or hairs which perform the same function and hence are scent receptors. The Monarch butterflies, and other genera of the same family, possess a more specialized structure. Although acting in a like manner to that of clusters of hairs or scales, these specialized receptors possess a spongy material which acts like a blotter, and, in order to retain the fluid producing the odour for a longer period of time, the receptor is covered with a roof of scales as well as a heavy chitinous membrane. This arrangement permits a longer period of time for the male to grasp the female. The liquid applied to exposed hair or scale clusters would volatilize much more rapidly than that contained in such a pocket.

We can now more readily understand why specialized hair clusters and scales are usually located on the hind wings within easy reach of the tip of the abdomen. We can understand the reason for de Niceville's observation, recorded in the Journal and Proceedings of the Asiatic Society of Bengal, vol. 41: "The males (Euploeinae) may often be observed patrolling a small aerial space, with the end of the abdomen curled under the body toward the thorax, and with the two beautiful yellow anal tufts of long hairs distended to their fullest extent at right angles to the body." It also explains the observation of Müller that in D. erippus "a very small portion of the wing, close to the orifice of the sexual cavity, was entirely denuded of scales as if they had been repeatedly rubbed away by introducing something into the slit." In this species, the area referred to is slightly concave, forming a cup-like depression which received the drop of fluid from the anal glands and hence is a further specialization as compared to that found on the wing of the Monarch butterfly. It also explains why in some butterflies a patch of scales on the hind wings may be covered by a similar patch on the underside of the front wings because this mechanism would assist in preventing rapid volatilization of the scentproducing fluid until it was needed, and this interpretation would account for the presence of a strong odour when the wings were separated. Finally, the present interpretation will, I feel confident, explain many of the observations which have been made relative to the mating flight (as in the case of the graylings) of many species of butterflies, the presence of hair and scale clusters on parts of the body, and the presence or absence of odours during certain seasons of the year and under certain conditions as here outlined. 


\section{Bibliography}

Many papers have been published concerning the presence and possible function of the scent receptors on the wings of butterflies. For a summary of pertinent information and discussions I suggest the following two publications.

LONGSTAFF, G. B.

1912. Butterfly hunting in many lands. Longmans, Green and Co., New York.

SCUDDER, S. H.

1889. Butterflies of the eastern United States and Canada, vol. 1. Published by the author, Cambridge, Mass. 

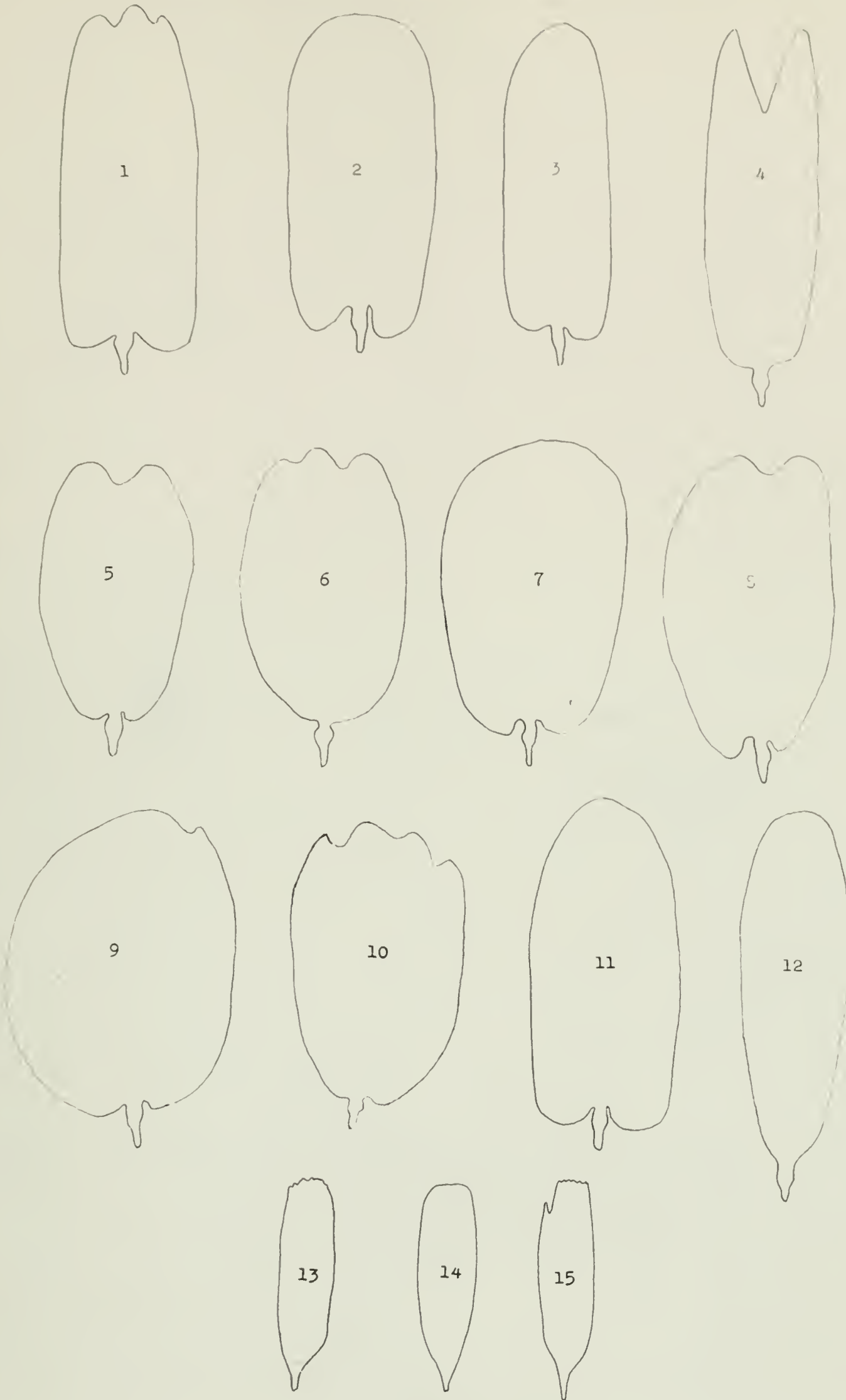

Plate I

Scales: 1-6 from wing membrane near opening to scent receptor; 7 - 8 from exterior roof covering of scent receptor; 9-11 from central area of wing; 12 from top of wing vein; $13-15$ from inside of scent receptor. 
16

R.O.M., \%. AND P. CONTRIBUTIONS

dorsal

scent receptor

and cub1tus vein
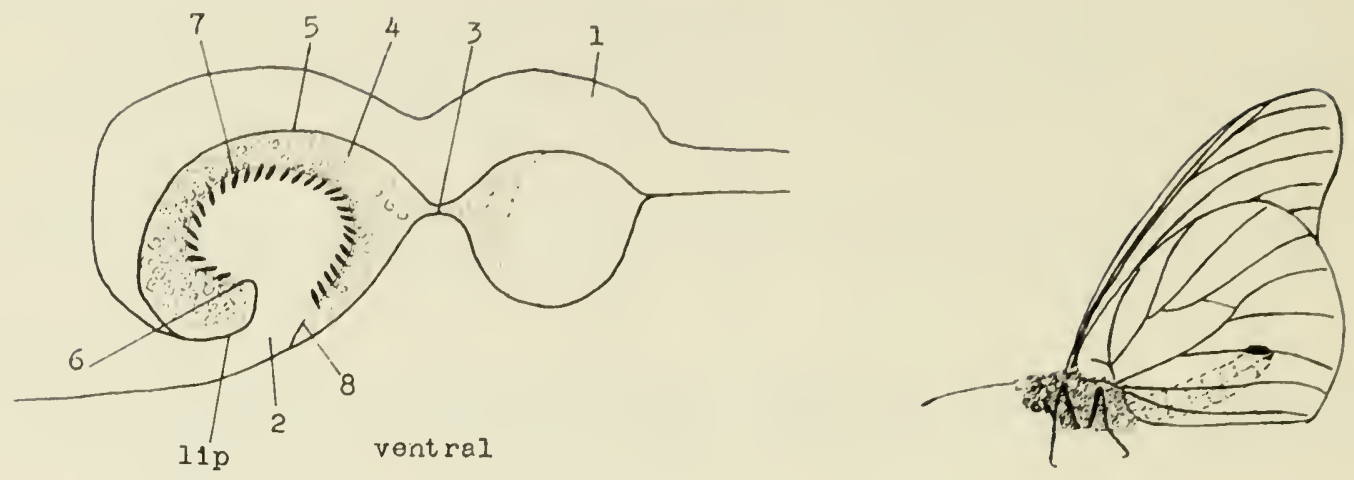

A

E

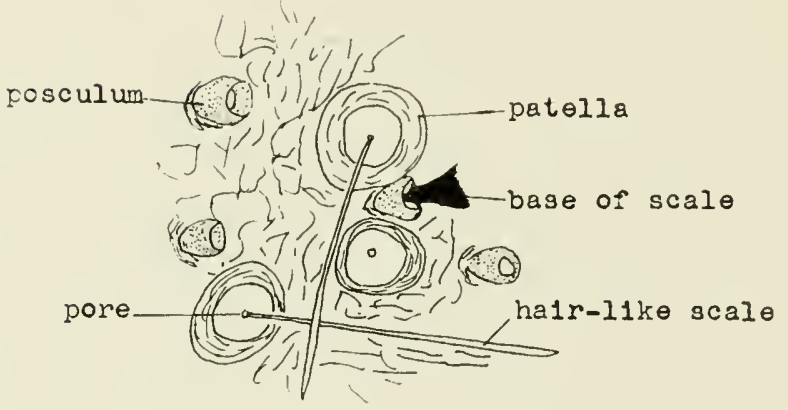

C

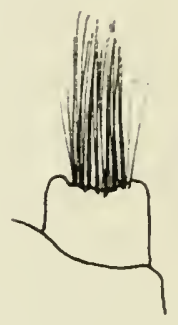

D

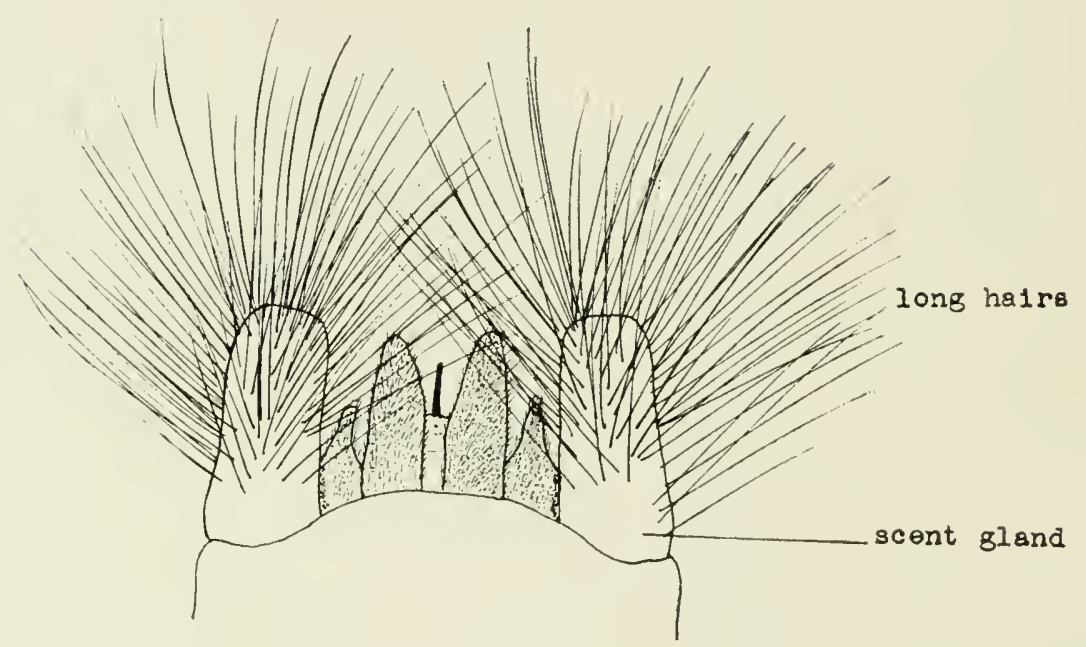

E

Plate II

A: transverse section through scent receptor of right rear wing; explanation of numbers given in text. B: left, lateral view of male Monarch showing position of tip of abdomen in relation to scent receptor. C: structures located within the cavity of the scent receptor. D: anal scent gland partly extruded. E: anal scent glands fully extruded. 



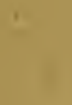

$=$

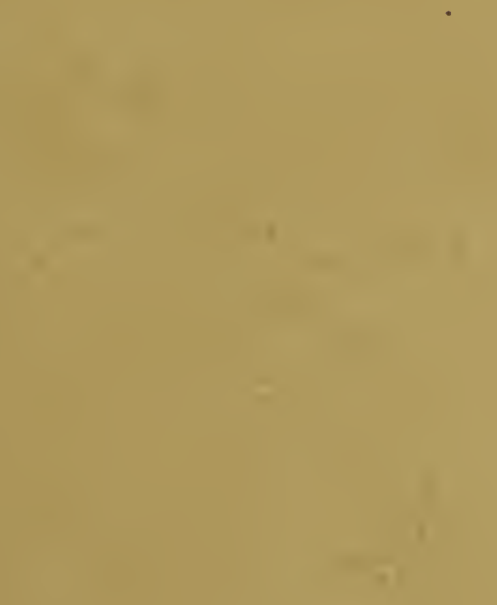

to

III

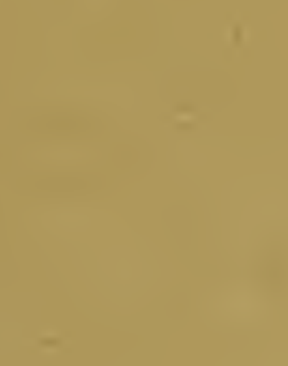

$$
x^{2}+2
$$


512 


Herom

bos

(1)

fon

3)

1.

ing

10

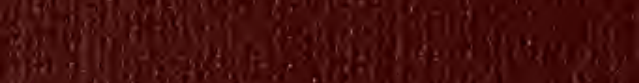

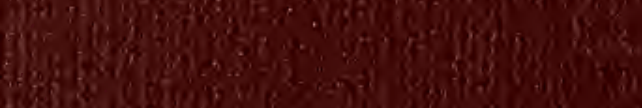

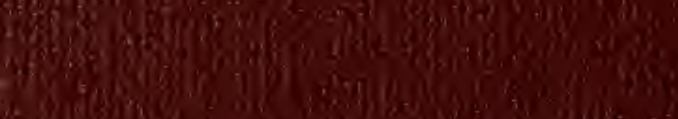

a) 1 (1) 